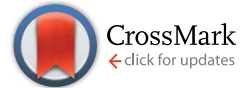

Cite this: Chem. Sci., 2017, 8, 1463

Received 12th August 2016

Accepted 10th October 2016

DOI: $10.1039 / \mathrm{c} 6 \mathrm{sc} 03614 \mathrm{~g}$

www.rsc.org/chemicalscience

\section{A family of cis-macrocyclic diphosphines: modular, stereoselective synthesis and application in catalytic $\mathrm{CO}_{2}$ /ethylene coupling ${ }^{\dagger}$}

\author{
Ioana Knopf, ${ }^{a}$ Daniel Tofan, ${ }^{a}$ Dirk Beetstra, ${ }^{\mathrm{b}}$ Abdulaziz Al-Nezari, ${ }^{\mathrm{b}}$ Khalid Al-Bahily ${ }^{\mathrm{b}}$ \\ and Christopher C. Cummins*a
}

\begin{abstract}
A family of cis-macrocyclic diphosphines was prepared in just three steps from white phosphorus and commercial materials using a modular synthetic approach. Alkylation of bicyclic diphosphane 3,4,8,9-tetramethyl-1,6-diphosphabicyclo(4.4.0)deca-3,8-diene, or $\mathrm{P}_{2}(\mathrm{dmb})_{2}$, produced phosphinophosphonium salts $\left[R-P_{2}(d m b)_{2}\right] X$, where $R$ is methyl, benzyl and isobutyl, in yields of $90-96 \%$. Treatment of these salts with organolithium or Grignard reagents yielded symmetric and unsymmetric macrocyclic diphosphines of the form cis-1-R-6-R'-3,4,8,9-tetramethyl-2,5,7,10-tetrahydro-1,6DiPhospheCine, or R, $R^{\prime}-D P C$, in which $R^{\prime}$ is methyl, cyclohexyl, phenyl or mesityl, in yields of $46-94 \%$. Alternatively, symmetric diphosphine $\mathrm{Cy}_{2}$-DPC was synthesized in $74 \%$ yield from the dichlorodiphosphine $\mathrm{Cl}_{2} \mathrm{P}_{2}(\mathrm{dmb})_{2}$. As a first application, these cis-macrocyclic diphosphines were used as ligands in the nickel-catalyzed synthesis of acrylate from $\mathrm{CO}_{2}$ and ethylene, for which they showed promising catalytic activity.
\end{abstract}

While chelating diphosphines have established a wide range of uses in areas from fundamental chemistry to catalysis, ${ }^{1}$ macrocyclic diphosphines are an underrepresented class of ligands. Their scarcity is primarily due to challenges associated with their synthesis. Macrocycles containing two or more phosphorus atoms exhibit multiple stereoisomers since the phosphines, which are locked in place by the cyclic framework, have a high barrier to inversion. Typically, syntheses of macrocyclic diphosphines yield mixtures of diastereomers; ${ }^{2,3}$ stereoselective syntheses of either cis or trans macrocyclic diphosphines are rare. ${ }^{4,5}$ While synthetically challenging, embedding one or more phosphorus atoms in a cyclic framework is desirable as it leads to more rigid and robust structures compared to their acyclic phosphine counterparts. ${ }^{6}$

cis-Macrocyclic diphosphines have been postulated to be "interesting ligands for transition metal complexes, comparable to, but perhaps usefully different from, the familiar range of chelating diphosphines", ${ }^{7}$ yet their coordination chemistry is essentially unexplored. ${ }^{8}$ In this context, it is useful to distinguish between medium-sized (7-12-membered rings) and large

${ }^{a}$ Department of Chemistry, Massachusetts Institute of Technology, 77 Massachusetts Avenue, Cambridge, MA 02139-4307, USA. E-mail: ccummins@mit.edu; Tel: +1 617 2535332

${ }^{b}$ SABIC CRD, Fundamental Catalysis, Thuwal 23955-6900, Saudi Arabia

$\dagger$ Electronic supplementary information (ESI) available: Full experimental, crystallographic and spectroscopic data. CCDC 1477899-1477902. For ESI and crystallographic data in CIF or other electronic format see DOI: 10.1039/c6sc03614g
(>12 membered rings) macrocyclic diphosphines. Complexes of large macrocyclic diphosphines have been synthesized as mixtures of diastereomers via ring closing metathesis and hydrogenation of preassembled metal complexes of transspanning monophosphines with pendant olefins. ${ }^{3}$ This synthetic strategy was also extended to prepare metal complexes of large trans-spanning macrobicyclic diphosphines. ${ }^{9}$ While both cis and trans isomers of a diphosphine embedded in a very large macrocycle can bind to a metal center, only the cis isomer can bind to a single metal center in medium-sized ring systems. The only medium-sized macrocyclic diphosphine with structurally characterized metal complexes is cis-1,5-diphenyl-1,5diphosphacyclooctane, a ligand obtained after tedious separation of the cis and trans diastereomers produced by the lithium aluminum hydride reduction of the corresponding phosphine oxides. $^{\mathbf{1 0}}$

The only stereoselective synthetic route to cis medium-sized macrocyclic diphosphines was reported by Alder et al. ${ }^{5}$ We were surprised to find no coordination complexes reported for these diphosphines, despite them being synthesized two decades ago. In the Alder synthesis, the desired cis-macrocyclic diphosphines are obtained by stereoselective cleavage of the $\mathrm{P}-\mathrm{P}$ bond in alkylated diphosphabicyclo[k.l.0]alkanes $(k=3-5, l=3-4)$ by organometallic reagents. These diphosphabicyclo[k.l.0]alkanes are prepared via a tedious procedure from diphosphinoalkanes $\mathrm{H}_{2} \mathrm{P}-\left(\mathrm{CH}_{2}\right)_{k}-\mathrm{PH}_{2}$, which in turn are prepared in two steps from the corresponding dibromoalkanes. While the bicyclic diphosphane framework is key to the stereoselectivity of the entire 
process, its assembly represents the most cumbersome part of the synthesis. Our group has recently accessed bicyclic diphosphanes in only one step from white phosphorus and commercial dienes under photochemical conditions. ${ }^{\mathbf{1 1 2}}$ For example, diphosphane 3,4,8,9-tetramethyl-1,6-diphosphabicyclo(4.4.0)deca-3,8-diene or $\mathrm{P}_{2}(\mathrm{dmb})_{2}(\mathbf{1})$ is obtained in gram quantities directly from white phosphorus and 2,3-dimethylbutadiene. ${ }^{\mathbf{1 1}}$ This synthesis is part of a greater endeavor pursued by our group ${ }^{\mathbf{1 3}}$ and others ${ }^{\mathbf{1 4}}$ to prepare phosphoruscontaining compounds in an atom economical fashion directly from $\mathrm{P}_{4},{ }^{15}$ the precursor to the more widely used phosphorus source $\mathrm{PCl}_{3}$.

We envisioned that alkylating 1 would yield phosphinophosphonium salts that would be prone to reacting with nucleophiles to break the $\mathrm{P}-\mathrm{P}$ bond. This process would afford cis-macrocyclic diphosphines in a stereoselective manner in only three steps from white phosphorus! We describe herein an expedited synthetic route to a family of cis-macrocyclic diphosphines that will facilitate investigating the coordination chemistry of these molecules and enable their use as ligands in catalysis.

We began this synthetic endeavor by investigating the alkylation of diphosphane 1 with methyl iodide (MeI). Previous studies have shown excellent selectivity in functionalizing only one of the phosphorus atoms in $\mathbf{1 .}^{\mathbf{1 6}}$ As expected, phosphinophosphonium salt $\left[\mathrm{Me}-\mathrm{P}_{2}(\mathrm{dmb})_{2}\right] \mathrm{I}(2)$ was obtained in $90 \%$ yield after treatment of $\mathbf{1}$ with methyl iodide in diethyl ether at room temperature overnight. The structure of $\left[\mathrm{Me}-\mathrm{P}_{2}(\mathrm{dmb})_{2}\right] \mathrm{I}$ was confirmed by X-ray crystallography (Fig. 2), and displayed a typical P-P single bond distance of 2.1862(17) A. Treatment of 1 with benzyl bromide ( $\mathrm{BnBr}$ ) also proceeded smoothly to give $\left[\mathrm{Bn}-\mathrm{P}_{2}(\mathrm{dmb})_{2}\right] \mathrm{Br}(3)$ in $96 \%$ yield after 2 hours at room temperature in dichloromethane (Fig. 1). The reaction of 1 with isobutyl bromide $\left({ }^{i} \mathrm{BuBr}\right)$ was more sluggish and required heating at $100{ }^{\circ} \mathrm{C}$ for $20 \mathrm{~h}$ in the presence of an excess of the alkyl halide in order to achieve full conversion to $\left[{ }^{i} \mathrm{Bu}-\mathrm{P}_{2}(\mathrm{dmb})_{2}\right]$ $\operatorname{Br}(4) .{ }^{17}$ All of these phosphino-phosphonium salts have characteristic ${ }^{31} \mathrm{P}\left\{{ }^{1} \mathrm{H}\right\}$ NMR spectra that show strong coupling

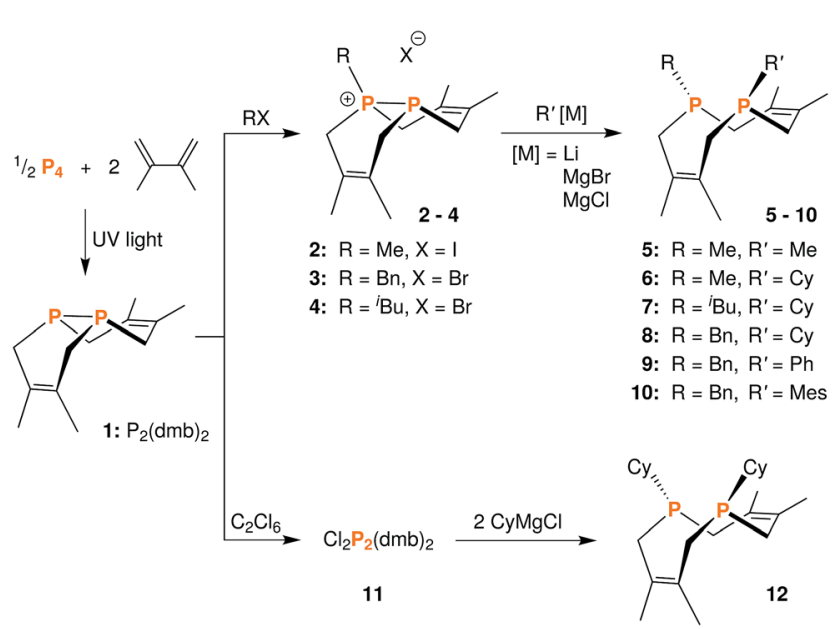

Fig. 1 Synthetic routes to phosphino-phosphonium salts 2-4, dichloride 11, and macrocyclic diphosphines 5-10 and 12 between the two phosphorus atoms. For example, the ${ }^{31} \mathrm{P}\left\{{ }^{1} \mathrm{H}\right\}$ NMR shifts of $\left[\mathrm{Me}-\mathrm{P}_{2}(\mathrm{dmb})_{2}\right] \mathrm{I}$ are $+44.7 \mathrm{ppm}$ and $-69.3 \mathrm{ppm}$, with a ${ }^{1} J_{\mathrm{PP}}=276 \mathrm{~Hz}$ (see Table $\mathrm{S} 1$ in ESI $\dagger$ for a summary of all the ${ }^{31} \mathrm{P}\left\{{ }^{1} \mathrm{H}\right\}$ NMR chemical shifts and coupling constants).

With these salts in hand, we began investigating their reactivity with organometallic reagents. Upon adding a methyllithium solution to a slurry of 2 in THF or diethyl ether at room temperature, a new signal indicative of cis-1,3,4,6,8,9-hexamethyl-2,5,7,10-tetrahydro-1,6-DiPhospheCine, or $\mathrm{Me}_{2}$-DPC (5), was observed by ${ }^{31} \mathrm{P}\left\{{ }^{1} \mathrm{H}\right\}$ NMR spectroscopy. A potential side reaction we had considered was deprotonation of the phosphino-phosphonium salt by methyllithium and formation of the Wittig reagent $\left(\mathrm{CH}_{2}\right) \mathrm{P}_{2}(\mathrm{dmb})_{2}$. However, no evidence was found for the formation of such an ylide by ${ }^{31} \mathrm{P}\left\{{ }^{1} \mathrm{H}\right\}$ NMR spectroscopy. Diphosphine $\mathbf{5}$ was also characterized by X-ray crystallography (Fig. 3), revealing a conformation with nearly $C_{2 \mathrm{v}}$ symmetry in which the phosphorus lone pairs are pointed away from each other.

Treatment of phosphino-phosphonium salts 2, 4, and 3 with cyclohexylmagnesium chloride led to the formation of Me,Cy-DPC (6), ${ }^{i} \mathrm{Bu}, \mathrm{Cy}-\mathrm{DPC}$ (7), and Bn,Cy-DPC (8), respectively (Fig. 1). All of these diphosphines can be isolated in yields of 90-94\% and they each show two distinct signals in their ${ }^{31} \mathrm{P}\left\{{ }^{1} \mathrm{H}\right\}$ NMR spectra, with small ${ }^{5} J_{\mathrm{PP}}$ coupling constants of $c a .5 \mathrm{~Hz}$. For example, the ${ }^{31} \mathrm{P}\left\{{ }^{1} \mathrm{H}\right\}$ NMR spectrum of 6 shows two signals at -38.9 and $-60.8 \mathrm{ppm}$. In order to demonstrate the versatility of this synthetic strategy, 3 was also treated with two aryl Grignard reagents, phenylmagnesium bromide and mesitylmagnesium bromide. The resulting diphosphines, Bn,Ph-DPC (9) and Bn,Mes-DPC (10), showed similar spectroscopic features to the dialkyl diphosphines described above.

While this modular approach had already enabled the synthesis of a variety of macrocyclic diphosphines, the initial alkylation step was limited to primary halide substrates. In order to overcome this limitation, we sought to add a dihalodiphosphine to our synthetic toolbox. This intermediate would

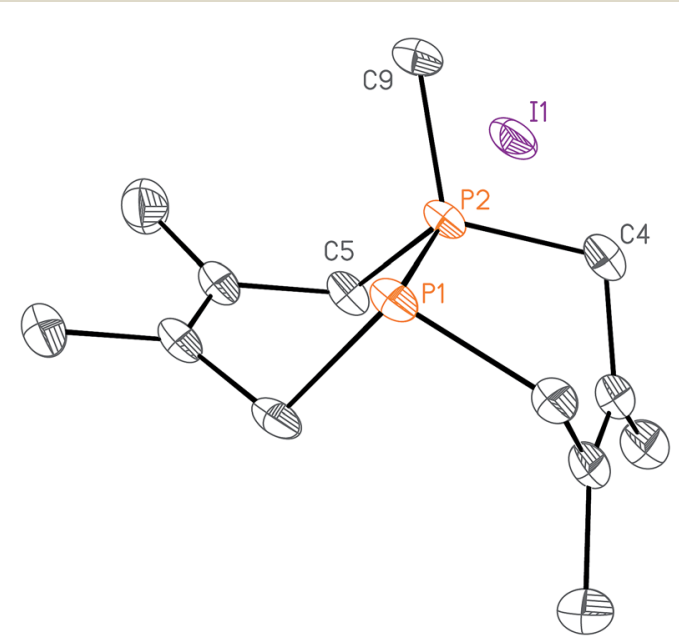

Fig. 2 Solid-state structure of $\left[\mathrm{Me}-\mathrm{P}_{2}(\mathrm{dmb})_{2}\right]$ l (2) with ellipsoids at the $50 \%$ probability level and disordered THF omitted for clarity. Representative interatomic distances $[\AA \AA]$ and angles $\left[^{\circ}\right]$ : P2-C4 1.813(5), P2C5 1.817(5), P2-C9 1.791(5), P1-P2 2.1862(17); C9-P2-C4 111.7(2), C9-P2-C5 106.9(2), C4-P2-C5 112.0(2), C9-P2-P1 114.01(19). 


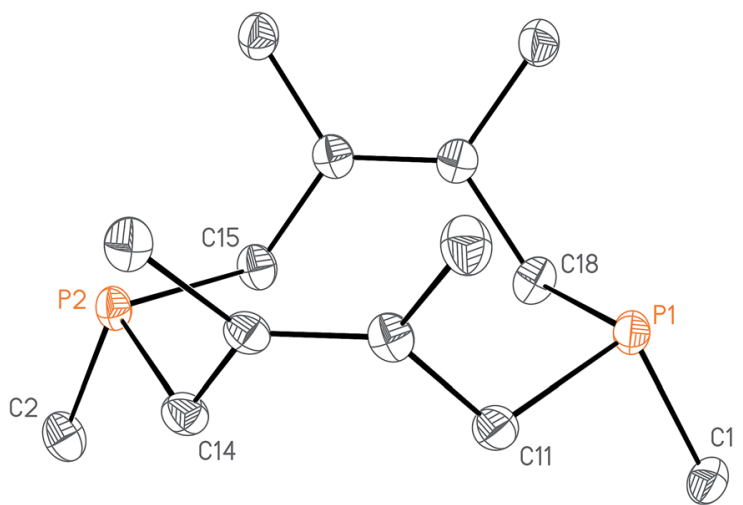

Fig. 3 Solid-state structure of $\mathrm{Me}_{2}$-DPC (5) with ellipsoids at the $50 \%$ probability level and hydrogen atoms omitted for clarity. Representative interatomic distances [ $[\AA]$ and angles $\left[^{\circ}\right]$ : P1-C1 1.8433(16), P1-C11 1.8583(16), P1-C18 1.8624(16), P2-C2 1.8421(17), P2-C15 1.8617(16), P2-C14 1.8630(16); C1-P1-C11 96.84(7), C1-P1-C18 98.07(7), C11P1-C18 101.22(7), C2-P2-C15 97.03(8), C2-P2-C14 98.02(7), C15P2-C14 101.54(7).

provide access to a symmetrical diphosphine upon addition of two equivalents of organometallic reagent. Treatment of 1 with iodine, a mild oxidant, did not yield a diiododiphosphine, but rather an iodine adduct, $\mathrm{I}_{2} \cdot \mathbf{1}$, which we were able to characterize by X-ray crystallography (Fig. 4). The elongated I-I distance of 3.4169(12) $\AA$ is similar to metrical data reported for other phosphine-iodine adducts. ${ }^{18}$ While several monophosphine-iodine adducts have been structurally characterized and described in the literature, ${ }^{18,19}$ this is an unusual example of a diphosphane-iodine adduct in which the P-P bond is still intact.

The reaction of 1 with many potent halogenating agents (e.g. bromine, $N$-bromosuccinimide, xenon difluoride) proved to be unselective, yet oxidation of $\mathbf{1}$ with hexachloroethane produced the desired $\mathrm{Cl}_{2} \mathrm{P}_{2}(\mathrm{dmb})_{2}(\mathbf{1 1})$ in good purity. We expected this

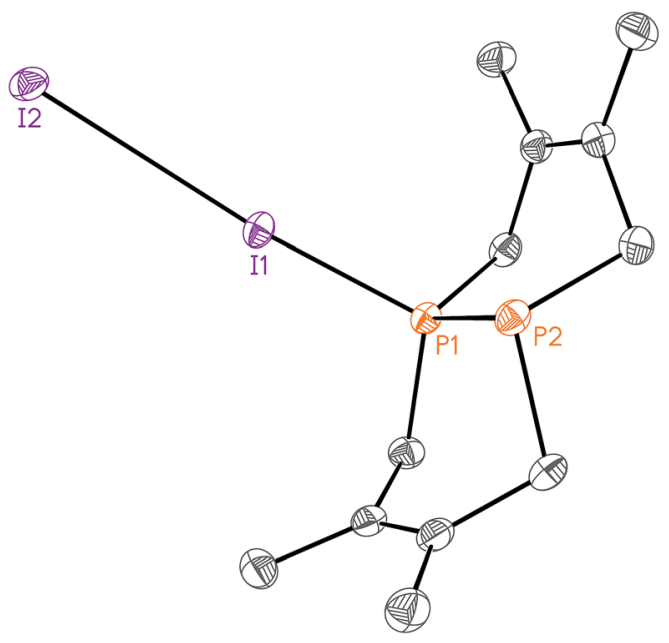

Fig. 4 Solid-state structure of $I_{2} \cdot P_{2}(d m b)_{2}\left(I_{2} \cdot 1\right)$ with ellipsoids at the $50 \%$ probability level and disordered solvent and iodine omitted for clarity. Representative interatomic distances $[\AA]]$ and angles $\left[^{\circ}\right]$ : I1-P1 2.4110(5), I1-12 3.4169(12), P1-P2 2.1913(7); P1-I1-I2 173.21(4). product to have a symmetrical open structure, as the P-P bond would have been cleaved upon oxidation. However, NMR spectroscopy suggests that $\mathbf{1 1}$ is best described as a chloronium chloride salt in equilibrium with the open form. At room temperature, signals are broad in both the ${ }^{1} \mathrm{H}$ NMR and ${ }^{31} \mathrm{P}\left\{{ }^{1} \mathrm{H}\right\}$ $\operatorname{NMR}\left(\Delta \nu_{1 / 2} \approx 1700 \mathrm{~Hz}\right)$ spectra of 11 ; upon cooling to $-40{ }^{\circ} \mathrm{C}$, the ${ }^{31} \mathrm{P}\left\{{ }^{1} \mathrm{H}\right\}$ NMR spectrum shows two distinct phosphorus environments at $+143.4 \mathrm{ppm}$ and $-48.7 \mathrm{ppm}$ with a ${ }^{1} J_{\mathrm{PP}}=$ $291 \mathrm{~Hz}$. In order to elucidate whether the broad NMR signals were due to chloride association/dissociation at the same phosphorus center versus chloride-mediated P-P bond scission/ reformation, a 2D EXSY (EXchange SpectroscopY) experiment was performed. ${ }^{20}$ In the first pathway, the two phosphorus centers would remain distinct throughout the exchange process, while in the second pathway the two phosphorus centers would become chemically equivalent in the open form. The ${ }^{31} \mathrm{P}\left\{{ }^{1} \mathrm{H}\right\}$ 2D EXSY spectrum of $\mathbf{1 1}$ (Fig. 5) clearly shows the presence of exchange cross peaks, thus supporting the chemical exchange pathway depicted in the same figure. The proposed role of free chloride in the exchange was corroborated by treatment of $\mathbf{1 1}$ with $\mathrm{GaCl}_{3}$, which sequestered the chloride into the tetrachlorogallate $\left[\mathrm{GaCl}_{4}\right]^{-}$anion; this inhibited the exchange process and "froze" the compound in the chloronium salt form with sharp ${ }^{31} \mathrm{P}\left\{{ }^{1} \mathrm{H}\right\}$ NMR resonances at room temperature.

Addition of two equivalents of cyclohexylmagnesium chloride to a suspension of $\mathbf{1 1}$ in diethyl ether or THF results in the formation of the desired $\mathrm{Cy}_{2}$-DPC (12). The ${ }^{31} \mathrm{P}\left\{{ }^{1} \mathrm{H}\right\}$ NMR spectrum of this product reveals a characteristic singlet resonance at $-38.7 \mathrm{ppm}$ for 12, but also a small amount of $\mathbf{1}(c a .2 \%)$. This byproduct is likely due to the reduction of $\mathbf{1 1}$ under the reaction conditions. While reduction was not a major reaction pathway during the formation of $\mathbf{1 2}$, it became problematic when attempting to prepare ${ }^{t} \mathrm{Bu}_{2}$-DPC. Treatment of $\mathbf{1 1}$ with tert-butylmagnesium chloride resulted in a roughly equimolar mixture of ${ }^{t} \mathrm{Bu}_{2}$-DPC and $\mathbf{1}$. Due to their similar solubility properties, these two products could not be separated.

While all syntheses were conducted under inert atmosphere, we wondered if these new diphosphines had any stability to air

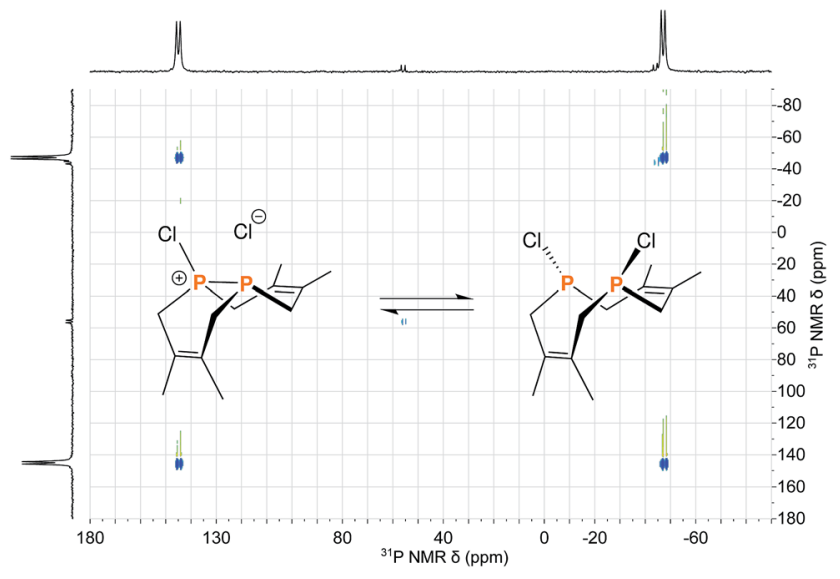

Fig. 5 Reaction scheme depicting the equilibrium between the two structural forms of 11 overlayed on the ${ }^{31} \mathrm{P}\left\{{ }^{1} \mathrm{H}\right\} 2 \mathrm{D}$ EXSY spectrum of 11 acquired at $0{ }^{\circ} \mathrm{C}$ in $\mathrm{CDCl}_{3}$. 
and moisture. Exposing a benzene- $d_{6}$ solution of $\mathbf{1 2}$ to air led to no visible changes by ${ }^{31} \mathrm{P}$ NMR spectroscopy even after 24 hours. This diphosphine proved to be remarkably robust, as less than $10 \%$ of the material had decomposed to the phosphine-phosphine oxide after 48 hours in solution.

Having accessed a family of new chelating macrocyclic diphosphines, we were interested in exploring their use as supporting ligands in a catalytic process. Given our interest in $\mathrm{CO}_{2}$ utilization, ${ }^{21}$ we turned to the coupling of $\mathrm{CO}_{2}$ and ethylene as a first application. While formation of nickelalactones from $\mathrm{Ni}(0)$ species, $\mathrm{CO}_{2}$ and ethylene had been known since the $1980 \mathrm{~s}$ from the pioneering work of Hoberg and coworkers, ${ }^{22}$ the first catalytic system to produce acrylate from this coupling was only reported in 2012. ${ }^{23,24}$ The stability of nickelalactones has been one of the major challenges in assembling a catalytic process; conversion of a nickelalactone to its corresponding nickel acrylate complex requires both a base and an alkali metal Lewis acid. ${ }^{23,25,26}$ Furthermore, extensive ligand screening has shown that only a small, select group of electron-rich diphosphines gives rise to any catalytic activity whatsoever. ${ }^{27,28}$ Despite the progress made in the last few years, typical turnover numbers are in the double digits and only extensively optimized systems yield turnover numbers greater than $100 .^{28}$

In order to test whether these cis-macrocyclic diphosphines could support a nickelalactone, we prepared (Fig. 6) and crystallographically characterized the nickelalactone of $12,\left(\mathrm{Cy}_{2}-\right.$ DPC)Ni( $\left.\mathrm{CH}_{2} \mathrm{CH}_{2} \mathrm{COO}\right)$ (13) (Fig. 7). The Ni1-C3 and Ni1-O1 distances of $1.982(6)$ and $1.899(4) \AA$, respectively, are similar to those reported for other nickelalactones. ${ }^{29}$ The bite angle of the diphosphine in complex 13 is $91.46(5)^{\circ}$, a value intermediate between that observed for the lactone of dicyclohexylphosphinoethane (dcpe), namely $88.07(5)^{\circ},{ }^{26}$ and that observed for the lactone of diphenylphosphinobutane (dppb), namely $93.91(4)^{\circ} \cdot{ }^{29}$ The smaller bite angle compared to dppb, a ligand that also has a four carbon atom bridge, might be due to the increased backbone rigidity of $\mathbf{1 2}$.

While helpful for comparing 12 with other ligands previously used to support nickelalactones, bite angle is an insufficient metric for describing the steric profile of $\mathbf{1 2}$. The cyclic backbone of this ligand renders an unusual placement of the cyclohexyl substituents in the $\mathrm{P}-\mathrm{Ni}-\mathrm{P}$ plane, a feature best described by the P1-Ni1-P2-C41 and P2-Ni1-P1-C31 torsion angles of $-173.1(2)^{\circ}$ and $175.33(18)^{\circ}$, respectively. In contrast, a ligand such as dcpe places its backbone linker in the P-Ni-P plane, and the cyclohexyl substituents above and below that plane (Fig. 8). The absolute values of the corresponding $\mathrm{P}-\mathrm{Ni}-\mathrm{P}-\mathrm{C}$ torsion angles in (dcpe) $\mathrm{Ni}\left(\mathrm{CH}_{2} \mathrm{CH}_{2} \mathrm{COO}\right)$ range from $96.6^{\circ}$ to

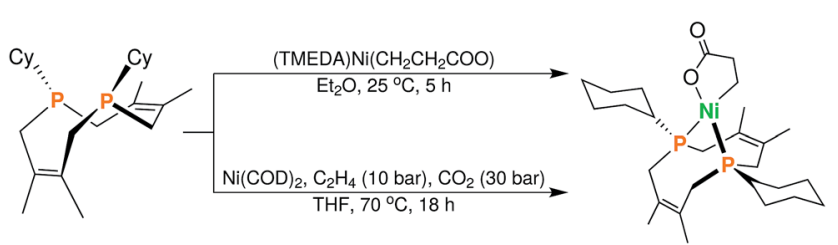

Fig. 6 Synthesis of $\left(\mathrm{Cy}_{2}-\mathrm{DPC}\right) \mathrm{Ni}\left(\mathrm{CH}_{2} \mathrm{CH}_{2} \mathrm{COO}\right)$ (13) from 12 via two complementary routes (see ESI† for details).

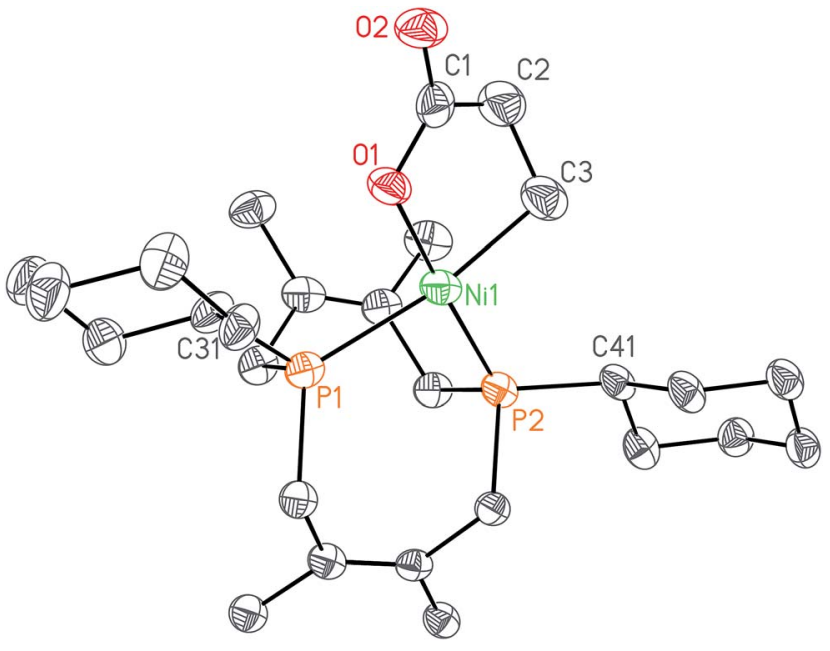

Fig. 7 Solid-state structure of nickelalactone $\left(\mathrm{Cy}_{2}-\mathrm{DPC}\right) \mathrm{Ni}\left(\mathrm{CH}_{2} \mathrm{CH}_{2}\right.$ COO) (13) with ellipsoids at the $50 \%$ probability level and hydrogen atoms omitted for clarity. Representative interatomic distances $[\AA \AA]$ and angles [ ${ }^{\circ}$ ]: Ni1-P1 2.2454(15), Ni1-P2 2.1283(15), Ni1-C3 1.982(6), Ni1O1 1.899(4), O1-C1 1.283(6), O2-C1 1.225(6); O1-Ni1-P1 90.86(12), O1-Ni1-C3 85.3(2), C3-Ni1-P2 92.56(19), P2-Ni1-P1 91.46(5); P1Ni1-P2-C41-173.1(2), P2-Ni1-P1-C31 175.33(18).

$136.7^{\circ}$, and average $117^{\circ} .^{26}$ In effect, 12 has its cyclohexyl substituents rotated by $60^{\circ}$ compared to a typical diphosphine such as depe.

In order to further probe the comparison between dcpe and 12, their $\%$ buried volumes $\left(\% V_{\text {bur }}\right.$, defined as the percent

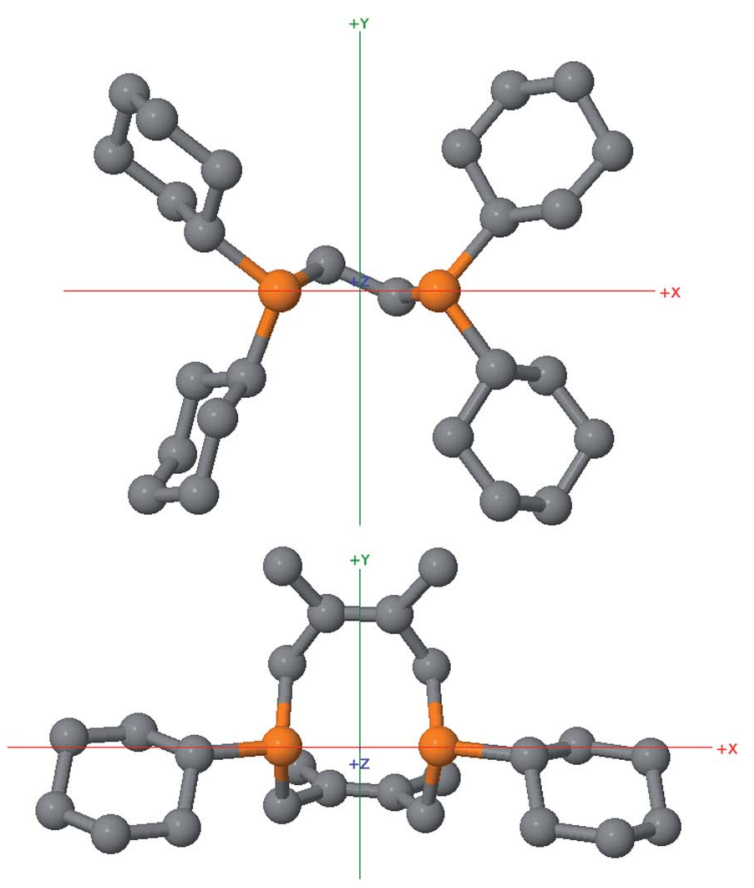

Fig. 8 Ball and stick models of dcpe (top) and $\mathrm{Cy}_{2}$-DPC (bottom) with hydrogen atoms omitted for clarity, highlighting the differences in steric profiles between these two diphosphines. Both ligands are viewed along the $Z$ axis, defined using SambVca 2.0 as the P-Ni-P angle bisector in their respective nickelalactone complexes. 
volume occupied by the ligand out of the total volume of a sphere centered at the metal and typically set to have a $3.5 \AA$ radius $)^{30}$ were calculated ${ }^{31}$ using the SambVca 2.0 web application developed by Cavallo and coworkers. ${ }^{32}$ Even though dcpe has four cyclohexyl substituents and $\mathbf{1 2}$ has only two, these ligands have almost identical \% buried volumes: $54.5 \%$ and $54.8 \%$, respectively. This result can be in part attributed to the unusual placement of the cyclohexyl groups in $\mathbf{1 2}$ with respect to the metal center, but also to the significant bulk added by the protruding methyl groups of the tetramethyltetrahydroDiPhospheCine (DPC) backbone.

Having determined that nickelalactones are accessible with this new ligand platform, we proceeded in measuring the catalytic activity of diphosphines 5-10 and 12. In doing so, we used two different protocols: one adapted from the work of Vogt et al. (method A), ${ }^{25}$ and one adapted from Limbach et al. (method B). ${ }^{27}$ In a typical catalytic run, $\mathrm{Ni}(\mathrm{COD})_{2}$ was mixed with the ligand, along with a base, Lewis acid, and zinc as an additive. For runs using method $\mathrm{A}$, the base was $\mathrm{NEt}_{3}$ and the Lewis acid was LiI, whereas for runs using method B, sodium 2-fluorophenoxide served as both the base and source of Lewis acid. As shown in Table 1, all of the new ligands but the bulky Bn,Mes-DPC (10) showed catalytic activity in this transformation. Dicyclohexylphosphinoethane (dcpe), dicyclohexylphosphinopropane (dcpp) and dicyclohexylphosphinobutane (dcpb) were used as benchmarks, as they are some of the best performing ligands reported in the literature so far. ${ }^{25,27} \mathrm{We}$ found the turnover numbers of our most active ligands such as 12 to be comparable to or better than those of the benchmark

Table 1 Catalytic acrylate production from $\mathrm{CO}_{2}$ and ethylene

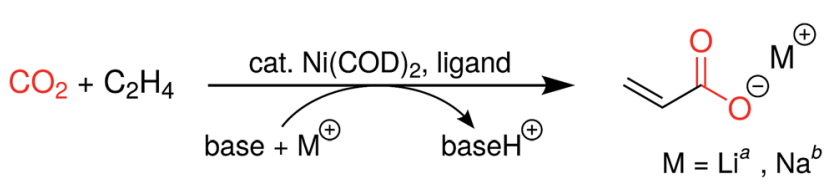

\begin{tabular}{lll}
\hline Ligand & TON $^{a}$ & TON $^{b}$ \\
\hline $\mathrm{Me}_{2}$-DPC (5) & 1 & 6 \\
$\mathrm{Me}, \mathrm{Cy}$-DPC (6) & 4 & 15 \\
${ }^{i} \mathrm{Bu}, \mathrm{Cy}-\mathrm{DPC}(\mathbf{7})$ & 10 & 11 \\
$\mathrm{Bn}, \mathrm{Cy}-\mathrm{DPC}(\mathbf{8})$ & 9 & 17 \\
$\mathrm{Bn}, \mathrm{Ph}-\mathrm{DPC}(\mathbf{9})$ & 12 & 4 \\
$\mathrm{Bn}, \mathrm{Mes}-\mathrm{DPC}(\mathbf{1 0})$ & 0 & 0 \\
$\mathrm{Cy}$-DPC (12) & 12 & $19(16)^{c}$ \\
$\mathrm{Cy}_{2} \mathrm{P}-\left(\mathrm{CH}_{2}\right)_{2}-\mathrm{PCy}$ (dcpe) & 8 & 12 \\
$\mathrm{Cy}_{2} \mathrm{P}-\left(\mathrm{CH}_{2}\right)_{3}-\mathrm{PCy}_{2}$ (dcpp) & 18 & 7 \\
$\mathrm{Cy}_{2} \mathrm{P}-\left(\mathrm{CH}_{2}\right)_{4}-\mathrm{PCy}_{2}$ (dcpb) & 6 & 4
\end{tabular}

${ }^{a} \mathrm{Ni}(\mathrm{COD})_{2}(0.05 \mathrm{mmol})$, ligand $(0.05 \mathrm{mmol}), \mathrm{Zn}(2.5 \mathrm{mmol})$, LiI $(1.25$ mmol), $\mathrm{NEt}_{3}(2.5 \mathrm{mmol})$, PhCl $(2 \mathrm{~mL})$, pressurized with $\mathrm{C}_{2} \mathrm{H}_{4}(25 \mathrm{bar})$ and $\mathrm{CO}_{2}(5 \mathrm{bar})$ and heated to $50{ }^{\circ} \mathrm{C}$ for $24 \mathrm{~h}$. The TONs listed are averages of two independent runs. ${ }^{b} \mathrm{Ni}(\mathrm{COD})_{2}(0.07 \mathrm{mmol})$, ligand $(0.077 \mathrm{mmol}), \mathrm{Zn}(3.5 \mathrm{mmol})$, sodium 2-fluorophenoxide $(3.5 \mathrm{mmol})$, THF $(10 \mathrm{~mL})$, pressurized with $\mathrm{C}_{2} \mathrm{H}_{4}(10 \mathrm{bar})$ and $\mathrm{CO}_{2}(10 \mathrm{bar})$ and heated to $100{ }^{\circ} \mathrm{C}$ for $20 \mathrm{~h} .{ }^{c}$ Complex $13(0.07 \mathrm{mmol})$ was used as the starting nickel source in lieu of the typical mixture of $\mathrm{Ni}(\mathrm{COD})_{2}$ and ligand. ligands. Notably, 12 performed significantly better than dcpb, a ligand that has a similar 4-carbon atom backbone.

Employing this new family of cis-macrocyclic diphosphines in $\mathrm{CO}_{2}$ /ethylene coupling is only the first step in exploring the catalytic relevance of these compounds. We plan to expand this ligand family using the synthetic methods disclosed herein, which have laid the groundwork for accessing phosphorusbased ligands with unique structures and steric profiles in a modular fashion. Asymmetric ligands will be easily accessible by installing chiral groups on the phosphorus centers, thus enabling numerous applications in the realm of asymmetric catalysis. Given the unusual steric profiles of the cis-macrocyclic diphosphines reported herein, our group is also actively pursuing the synthesis and characterization of a variety of metal complexes supported by these ligands in order to learn more about their coordination chemistry.

\section{Acknowledgements}

SABIC (Saudi Basic Industries Corporation) is acknowledged for funding this work. DT was funded by the National Science Foundation under CHE-1111357, renewed as CHE-1362118. Dr Bruce Adams is acknowledged for help with 2D NMR data acquisition. Prof. Dr Hansjörg Grützmacher is acknowledged for helpful discussions. X-ray diffraction data were collected on an instrument purchased with the aid of the National Science Foundation (NSF) under CHE-0946721.

\section{References}

1 J. Hartwig, Organotransition Metal Chemistry: From Bonding to Catalysis, University Science books, 1st edn, 2010.

2 (a) T. H. Chan and B. S. Ong, J. Org. Chem., 1974, 39, 17481752; (b) S. N. Ignat'eva, A. S. Balueva, A. A. Karasik, D. V. Kulikov, A. V. Kozlov, S. K. Latypov, P. Lönnecke, E. Hey-Hawkins and O. G. Sinyashin, Russ. Chem. Bull., 2007, 56, 1828-1837; (c) L. Horner, P. Walach and H. Kunz, Phosphorus, Sulfur Silicon Relat. Elem., 1978, 5, 171-184.

3 (a) E. B. Bauer, J. Ruwwe, J. M. Martin-Alvarez, T. B. Peters, J. C. Bohling, F. A. Hampel, S. Szafert, T. Lis and J. A. Gladysz, Chem. Commun., 2000, 2261-2262; (b) T. Shima, E. B. Bauer, F. Hampel and J. A. Gladysz, Dalton Trans., 2004, 1012-1028.

4 R. W. Alder, C. Ganter, C. J. Harris and A. G. Orpen, J. Chem. Soc., Chem. Commun., 1992, 1170-1172.

5 (a) R. W. Alder, D. D. Ellis, J. K. Hogg, A. Martín, A. G. Orpen and P. N. Taylor, Chem. Commun., 1996, 537-538; (b) R. W. Alder, C. Ganter, M. Gil, R. Gleiter, C. J. Harris, S. E. Harris, H. Lange, A. G. Orpen and P. N. Taylor, J. Chem. Soc., Perkin Trans. 1, 1998, 1643-1656.

6 (a) D. Gudat, Sci. Synth., 2009, 42, 155-220; (b) A.-M. Caminade and J. P. Majoral, Chem. Rev., 1994, 94, 1183-1213; (c) C. D. Swor and D. R. Tyler, Coord. Chem. Rev., 2011, 255, 2860-2881.

7 R. W. Alder and D. Read, Coord. Chem. Rev., 1998, 176, 113133. 
8 The 1998 review article cited above mentions unpublished observations vis-a-vis the ligand behaviour of the cismacrocyclic diphosphines synthesized by Alder et al.

9 (a) T. Shima, F. Hampel and J. A. Gladysz, Angew. Chem., Int. Ed., 2004, 43, 5537-5540; (b) A. J. Nawara, T. Shima, F. Hampel and J. A. Gladysz, J. Am. Chem. Soc., 2006, 128, 4962-4963; (c) L. Wang, T. Shima, F. Hampel and J. A. Gladysz, Chem. Commun., 2006, 4075-4077; (d) G. D. Hess, F. Hampel and J. A. Gladysz, Organometallics, 2007, 26, 5129-5131; (e) K. Skopek and J. A. Gladysz, J. Organomet. Chem., 2008, 693, 857-866; $(f)$ A. J. NawaraHultzsch, M. Stollenz, M. Barbasiewicz, S. Szafert, T. Lis, F. Hampel, N. Bhuvanesh and J. A. Gladysz, Chem.-Eur. J., 2014, 20, 4617-4637.

10 B. W. Arbuckle and W. Musker, Polyhedron, 1991, 10, 415419.

11 D. Tofan and C. C. Cummins, Angew. Chem., Int. Ed., 2010, 49, 7516-7518.

12 M. Serrano-Ruiz, A. Romerosa and P. Lorenzo-Luis, Eur. J. Inorg. Chem., 2014, 1587-1598.

13 (a) B. M. Cossairt, N. A. Piro and C. C. Cummins, Chem. Rev., 2010, 110, 4164-4177; (b) B. M. Cossairt and C. C. Cummins, New J. Chem., 2010, 34, 1533-1536.

14 (a) M. Scheer, G. Balázs and A. Seitz, Chem. Rev., 2010, 110, 4236-4256; (b) M. Caporali, L. Gonsalvi, A. Rossin and M. Peruzzini, Chem. Rev., 2010, 110, 4178-4235; (c) S. Heinl, S. Reisinger, C. Schwarzmaier, M. Bodensteiner and M. Scheer, Angew. Chem., Int. Ed., 2014, 53, 7639-7642.

15 C. C. Cummins, Daedalus, 2014, 143, 9-20.

16 (a) D. Tofan, M. Temprado, S. Majumdar, C. D. Hoff and C. C. Cummins, Inorg. Chem., 2013, 52, 8851-8864; (b) D. Tofan, Ph.D. thesis, Massachusetts Institute of Technology, 2013.

17 Secondary halides such as cyclohexyl bromide did not react with 1 under similar conditions.

18 (a) N. Bricklebank, S. M. Godfrey, H. P. Lane, C. A. McAuliffe, R. G. Pritchard and J.-M. Moreno, J. Chem. Soc., Dalton Trans., 1995, 2421-2424; (b) S. M. Godfrey, C. A. McAuliffe, R. G. Pritchard and J. M. Sheffield, J. Chem. Soc., Dalton Trans., 1998, 1919-1924.

19 (a) S. M. Godfrey, D. G. Kelly, C. A. Mcauliffe, A. G. Mackie, R. G. Pritchard and S. M. Watson, J. Chem. Soc., Chem. Commun., 1991, 1163-1164; (b) F. Teixidor, R. Núñez, C. Viñas, R. Sillanpää and R. Kivekäs, Angew. Chem., Int. Ed., 2000, 39, 4290-4292; (c) B. D. Ellis and C. L. B. Macdonald, Inorg. Chem., 2006, 45, 6864-6874; (d) N. A. Barnes, S. M. Godfrey, R. T. A. Halton, I. Mushtaq and R. G. Pritchard, Dalton Trans., 2006, 4795-4804; (e) N. A. Barnes, K. R. Flower, S. A. Fyyaz, S. M. Godfrey, A. T. McGown, P. J. Miles, R. G. Pritchard and J. E. Warren, CrystEngComm, 2010, 12, 784-794; (f) N. A. Barnes, K. R. Flower, S. M. Godfrey, P. A. Hurst, R. Z. Khan and
R. G. Pritchard, CrystEngComm, 2010, 12, 4240-4251; $(g)$ N. A. Barnes, S. M. Godfrey, R. Z. Khan, A. Pierce and R. G. Pritchard, Polyhedron, 2012, 35, 31-46.

20 (a) C. L. Perrin and T. J. Dwyer, Chem. Rev., 1990, 90, 935967; (b) H. Bircher, B. R. Bender and W. Vonphilipsborn, Magn. Reson. Chem., 1993, 31, 293-298; (c) E. R. Civitello, P. S. Dragovich, T. B. Karpishin, S. G. Novick, G. Bierach, J. F. O'Connell and T. D. Westmoreland, Inorg. Chem., 1993, 32, 237-241; (d) A. Gogoll, J. Örnebro, H. Grennberg and J.-E. Bäckvall, J. Am. Chem. Soc., 1994, 116, 3631-3632.

21 (a) J. S. Silvia and C. C. Cummins, J. Am. Chem. Soc., 2010, 132, 2169-2171; (b) J. S. Silvia and C. C. Cummins, Chem. Sci., 2011, 2, 1474-1479; (c) I. Knopf, T. Ono, M. Temprado, D. Tofan and C. C. Cummins, Chem. Sci., 2014, 5, 1772-1776; (d) I. Knopf and C. C. Cummins, Organometallics, 2015, 34, 1601-1603.

22 (a) H. Hoberg and D. Schaefer, J. Organomet. Chem., 1983, 251, C51-C53; (b) H. Hoberg, Y. Peres and A. Milchereit, J. Organomet. Chem., 1986, 307, C41-C43; (c) H. Hoberg, Y. Peres, C. Kruger and Y.-H. Tsay, Angew. Chem., 1987, 99, 799-800.

23 M. L. Lejkowski, R. Lindner, T. Kageyama, G. É. Bódizs, P. N. Plessow, I. B. Müller, A. Schäfer, F. Rominger, P. Hofmann, C. Futter, S. A. Schunk and M. Limbach, Chem.-Eur. J., 2012, 18, 14017-14025.

24 S. Kraus and B. Rieger, Top. Organomet. Chem., 2016, 53, 199-224.

25 C. Hendriksen, E. A. Pidko, G. Yang, B. Schäffner and D. Vogt, Chem.-Eur. J., 2014, 20, 12037-12040.

26 D. Jin, P. G. Williard, N. Hazari and W. H. Bernskoetter, Chem.-Eur. J., 2014, 20, 3205-3211.

27 N. Huguet, I. Jevtovikj, A. Gordillo, M. L. Lejkowski, R. Lindner, M. Bru, A. Y. Khalimon, F. Rominger, S. A. Schunk, P. Hofmann and M. Limbach, Chem.-Eur. J., 2014, 20, 16858-16862.

28 S. Manzini, N. Huguet, O. Trapp and T. Schaub, Eur. J. Org. Chem., 2015, 7122-7130.

29 R. Fischer, J. Langer, A. Malassa, D. Walther, H. Görls and G. Vaughan, Chem. Commun., 2006, 2510-2512.

30 (a) A. Poater, F. Ragone, S. Giudice, C. Costabile, R. Dorta, S. P. Nolan and L. Cavallo, Organometallics, 2008, 27, 26792681; (b) H. Clavier and S. P. Nolan, Chem. Commun., 2010, 46, 841-861.

31 The $\% V_{\text {bur }}$ for both depe and $\mathbf{1 2}$ was calculated using the default settings in SambVca 2.0, namely bond radii scaled by 1.17 , sphere radius of $3.5 \AA$, $\mathrm{Ni}$ as the center of the sphere, mesh spacing for numerical integration of $0.1 \AA$, and $\mathrm{H}$ atoms not included.

32 (a) A. Poater, B. Cosenza, A. Correa, S. Giudice, F. Ragone, V. Scarano and L. Cavallo, Eur. J. Inorg. Chem., 2009, 17591766; (b) https://www.molnac.unisa.it/OMtools/sambvca2.0/. 